University of Nebraska - Lincoln

DigitalCommons@University of Nebraska - Lincoln

Roman L. Hruska U.S. Meat Animal Research

U.S. Department of Agriculture: Agricultural Center

Research Service, Lincoln, Nebraska

$2-5-2021$

\title{
Potential functional variants in AHR signaling pathways are associated with age at puberty in swine
}

Dan Nonneman

Clay A. Lents

Lea A. Rempel

Gary A. Rohrer

Follow this and additional works at: https://digitalcommons.unl.edu/hruskareports

This Article is brought to you for free and open access by the U.S. Department of Agriculture: Agricultural Research Service, Lincoln, Nebraska at DigitalCommons@University of Nebraska - Lincoln. It has been accepted for inclusion in Roman L. Hruska U.S. Meat Animal Research Center by an authorized administrator of DigitalCommons@University of Nebraska - Lincoln. 


\title{
Potential functional variants in $A H R$ signaling pathways are associated with age at puberty in swine ${ }^{\dagger, \neq}$
}

\author{
Dan Nonneman (D, Clay A. Lents, Lea A. Rempel and Gary A. Rohrer \\ USDA, ARS, U.S. Meat Animal Research Center, Clay Center, NE 68933, USA.
}

\section{Summary}

\begin{abstract}
Puberty in female pigs is defined as age at first estrus and gilts that have an earlier age at puberty are more likely to have greater lifetime productivity. Because age at puberty is predictive for sow longevity and lifetime productivity, but not routinely measured in commercial herds, it would be beneficial to use genomic or marker-assisted selection to improve these traits. A GWAS at the US Meat Animal Research Center (USMARC) identified several loci associated with age at puberty in pigs. Candidate genes in these regions were scanned for potential functional variants using sequence information from the USMARC swine population founder animals and public databases. In total, 135 variants (SNP and insertion/deletions) in 39 genes were genotyped in 1284 phenotyped animals from a validation population sired by Landrace and Yorkshire industry semen using the Agena MassArray system. Twelve variants in eight genes were associated with age at puberty $(P<0.005)$ with estimated additive SNP effects ranging from 1.6 to 5.3 days. Nine of these variants were non-synonymous coding changes in AHR, CYP1A2, OR2M4, SDCCAG8, TBC1D1 and ZNF608, two variants were deletions of one and four codons in aryl hydrocarbon receptor, $A H R$, and the most significant SNP was near an acceptor splice site in the acetyl-CoA carboxylase alpha, ACACA. Several of the loci identified have a physiological and a genetic role in sexual maturation in humans and other animals and are involved in AHR-mediated pathways. Further functional validation of these variants could identify causative mutations that influence age at puberty in gilts and possibly sow lifetime productivity.
\end{abstract}

Keywords aryl hydrocarbon receptor, puberty, SNP, swine

Address for correspondence

Dan Nonneman, USDA, ARS, US Meat Animal Research Center, Clay Center, NE 68933, USA.

E-mail: dan.nonneman@usda.gov

${ }^{\dagger}$ Mention of trade names or commercial products in this publication is solely for the purpose of providing specific information and does not imply recommendation or endorsement by the US Department of Agriculture (USDA).

${ }^{\mp}$ The USDA prohibits discrimination in all its programs and activities on the basis of race, color, national origin, age, disability, and where applicable, sex, marital status, familial status, parental status, religion, sexual orientation, genetic information, political beliefs, reprisal, or because all or part of an individual's income is derived from any public assistance program. (Not all prohibited bases apply to all programs.) Persons with disabilities who require alternative means for communication of program information (Braille, large print, audiotape, etc.) should contact USDA's TARGET Center at (202) 720-2600 (voice and TDD). To file a complaint of discrimination, write to USDA, Director, Office of Civil Rights, 1400 Independence Avenue, S.W., Washington, DC 20250-9410, USA, or call (800) 795-3272 (voice) or (202) 7206382 (TDD). USDA is an equal opportunity provider and employer.

Accepted for publication 05 February 2021

\section{Introduction}

Reproductive failure accounts for the majority (about 30\%) of sow removals and most of these are in lower parities (Engblom et al. 2008). Gilts that reach puberty earlier tend to stay in the herd longer and be more productive (Patterson et al. 2010; Saito et al. 2011; Tart et al. 2013; Li et al. 2018). Genetic improvement of reproductive traits in pigs has been challenging because these traits are sexlimited, have low heritabilities and are not expressed until later in the animal's life. Selecting on causal genetic variants that affect these traits would accelerate genetic progress. Several association studies have focused on litter traits, such as litter size and number born alive (Uimari et al. 2011; Onteru et al. 2012; Schneider et al. 2012; BergfelderDruing et al. 2015; Trenhaile et al. 2016), and lifetime productivity (Onteru et al. 2011). Few associations overlap those from other studies or lie in known QTL regions, whereas most QTL are novel. These results for reproductive traits indicate differences in genetic architecture, the 
presence of a large number of loci with small effects and interactions with the environment. Other critical components of sow reproduction that are not routinely measured in industry settings include ovulation rate (Schneider et al. 2014), age at puberty (Tart et al. 2013; Nonneman et al. 2016) and delayed puberty (Nonneman et al. 2014).

Although fertility and reproductive longevity are important traits in swine and a great amount of effort has been expended to identify causative variation affecting these traits, limited success has been achieved. This study was designed to test associations of potentially functional variants in candidate genes previously identified in a GWAS for age at puberty (Nonneman et al. 2016).

\section{Materials and methods}

\section{Animals and phenotypic data collection}

All procedures involving animals were conducted using standard production practices that were in accordance with the Guide for the Care and Use of Agricultural Animals in Agricultural Research and Teaching (FASS 2010) and approved by the US Meat Animal Research Center (USMARC) Institutional Animal Care and Use Committee. Daily estrus detection was performed from 140 to 240 days of age using mature boars ( $>11$ months of age) placed in an alleyway between two pens of gilts, during which time herdsmen applied back pressure to gilts within each pen and gilts were observed for estrous behavior. Age at puberty was defined as the date on which the first standing estrus was detected. Gilts born during 2007-2014 ( $n=1284)$ with estrus dates were genotyped and used for the association study. Animals born in 2007-2010 were progeny from the original discovery population for the age at puberty GWAS (Nonneman et al. 2016), which was a Landrace-DurocYorkshire composite population (LDY), whereas animals born in 2011-2014 were derived from LDY females and sired by commercial semen from Landrace (born in oddnumbered years) and Yorkshire boars (born in evennumbered years) via artificial insemination (Table S1).

\section{Genomic association of variants with age at first estrus}

Candidate genes were identified from a previous GWAS for age at puberty (Nonneman et al. 2016). Potential functional variants in annotated genes were identified in the genomic sequence from USMARC founder sires (12 Duroc and 12 Landrace boars) and dams (48 Yorkshire-Landrace sows; Keel et al. 2017) of the original discovery population. Any potential functional variant in candidate genes annotated in reference assembly SSCROFA 10.2 that were predicted to alter an amino acid, splice site or regulatory region (transcription factor or miRNA binding site) was identified, and multiplex assays designed using MASSARRAY ASSAY DESIGN software (Agena) for 135 candidate SNPs in 39 genes. Genomic
DNA was extracted from tail tissue or semen (Wizard SV Genomic DNA Purification kit; Promega) of 1284 gilts with puberty records and their sires and dams $(n=1519$; Table S1). Genotypes were obtained using the Agena Massarray system with iPLEX chemistry (Agena; Table S2). Markers were filtered for genotyping rate less than $90 \%$, MAF less than 0.05 and HWE values less than $10^{-6}$.

A mixed-model REML analysis of genotypic associations was conducted where fixed effects included Year, Season (bimonthly) and Breed of sire (LDY, Landrace or Yorkshire; Wombat, http://didgeridoo.une.edu.au/km/wombat.php). Pedigree information was used to estimate polygenic effects including pedigrees, beginning in 2004. Marker effects were estimated as the additive effect of an allele substitution. There were 1284 animals with genotypic and phenotypic data and 2296 animals were included in the pedigree.

\section{Quantitative ddPCR}

Because AHR activation induces cytochrome P450 enzyme activity (Larigot et al. 2018) and variants in AHR have been shown to influence its own expression and the expression of genes downstream in AHR pathways (Helmig et al. 2011), the expression of genes associated with age at puberty (AHR, CYP1A1 and CYP1A2) was evaluated by droplet digital PCR (ddPCR). The ddPCR was performed on cDNA from liver tissue from a total of 39 fourth-parity sows (age $857 \pm 8.2$ days) collected in the luteal phase with equal distributions of the three AHR genotypes using a BioRad QX200 Droplet Digital PCR system (BioRad). Tissue was snap-frozen in liquid nitrogen and stored at $-80^{\circ} \mathrm{C}$ until extraction of RNA. Total RNA was isolated with Trizol reagent (Thermo Fisher Scientific Inc.) followed by column purification (Qiagen RNeasy mini kit; Qiagen) with DNase (RNase-Free DNase kits, Qiagen). Two micrograms of total RNA were reverse transcribed using GoScript Reverse Transcriptase (Promega) with random and oligo(dT) primers to obtain cDNA. The PCR reactions for AHR, CYP1A1, CYP1A2 and PPIA (peptidyl-prolyl cis-trans isomerase) were performed in duplicate using 0.4-10 ng cDNA using BioRad ddPCR EvaGreen Supermix and $100 \mathrm{~nm}$ primers, as shown in Table S3. Data were adjusted to copy number per nanogram of cDNA and normalized to PPIA expression. Statistical associations of SNP allelic effects and expression levels were performed using a mixed linear model analysis with sire line and season as covariates in the Golden Helix SNP and Variation Suite.

\section{Results}

A heritability of $30 \%$ for age at puberty was estimated for these data. Overall average age at puberty was $195.34 \pm 16.88$ days of age (Table S1). Age at first estrus was greater in gilts born in the July-August season than in 
other seasons (Fig. 1a). Gilts born from LDY sires $(n=482)$ reached puberty later than those sired by commercial Landrace $(n=557)$ or Yorkshire boars $(n=245$; Fig. $1 b)$.

\section{Genotypic associations}

After filtering of the 135 markers for MAF and HWE used for genotyping, 94 SNPs in 33 genes remained for analysis (Table S2). Most markers were removed because they were monomorphic or had a low MAF. Ten SNPs in six genes (ACACA, AHR, CYP1A2, OR2M4, SDCCAG8 and TBC1D1) were associated with age at puberty after Bonferroni correction $(P<0.0005$; Table 1 and Fig. 2). The estimated effects of allelic substitution ranged from -5.23 to 3.83 days. The most significant association was with an SNP located at -5 nucleotides in the acceptor site of intron 14 in the acetyl-CoA carboxylase alpha (ACACA) gene on SSC12 at $38.7 \mathrm{Mb}$ (rs321145963; Tables 1 and S2). Five non-synonymous SNPs and two indels in AHR were analyzed for age at puberty. Of these, four SNP and two indels are in exon 10 and one SNP is located in exon 11. Two of these SNPs (rs339939442 and rs339238482; Gly to Cys and Thr to Pro, respectively) were in relatively high LD $\left(r^{2}>0.95\right.$; Fig. 3$)$ and were among the SNPs most significantly associated with age at puberty (Table 1).
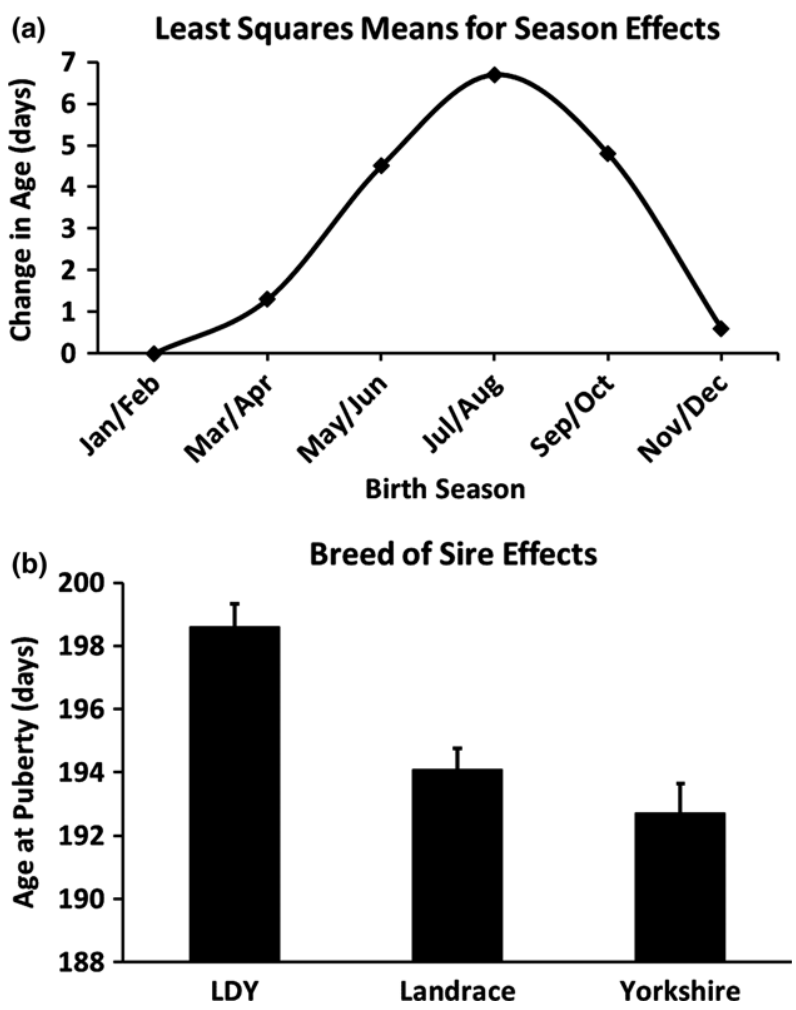

Figure 1 Effect of birth season (a) and sire breed (b) on age at puberty in days. Season refers to farrowing groups of 2 month seasons. Sire breeds were Landrace-Duroc-Yorkshire (LDY, $n=482$ ), Landrace $(n=557)$ and Yorkshire $(n=245)$.
Three non-synonymous SNP and two indels in the aryl hydrocarbon receptor $(A H R)$ on chromosome 9 at $86.5 \mathrm{Mb}$ were associated with age at puberty. A single non-synonymous SNP in CYP1A2, OR2M4 and TBC1D1 and a synonymous SNP in SDCCAG8 were also associated with age at puberty (Table 1).

Gene expression of AHR, CYP1A1 and CYP1A2 by AHR genotypes

Gene expression of AHR, CYP1A1 and CYP1A2 was normalized to expression of PPIA and was shown to be linear for the corresponding amount of cDNA provided in the reaction. Allelic associations for AHR and CYP1A1 were greatest for SNP rs696044913 (marker 9:95537388), a leucine codon deletion in exon 10 of AHR (Table 2). The allele associated with greater gene expression was also associated with a lower age at puberty (Table 1).

\section{Discussion}

Puberty in gilts is attained by a reduction of estrogen inhibition of the GnRH pulse generator, allowing increased LH pulses which leads to the onset of cyclicity (Lents et al. 2020) and is dependent upon ovarian follicular development, which can be affected by boar exposure, stress, feed or energy intake and growth rate (Zhuo et al. 2014; Matsuyama \& Kimura 2014; Knox 2019). It is reported here that season in which a gilt is born has a significant effect on the age at which she reaches puberty. The reason for this observed effect is presumed to be related to seasonal influence of prenatal programming of the litter, which has a cascade of effects on postnatal development in pigs (Foxcroft et al. 2009). The observed average age at puberty is consistent with reports for commercial gilts (Patterson et al. 2010; Calderón Díaz et al. 2015). Moreover, the estimated heritability for age at puberty is consistent with our previous report (Nonneman et al, 2016) and those previously reviewed by Rothschild and Bidanel (1998).

Variants in genes that affect the physiological or endocrine processes of hypothalamic function, follicular development, growth, body mass and nutrient utilization have been identified to be associated with age at menarche in humans (Day et al. 2015; Howard \& Dunkel, 2018). Age at menarche is analogous to age at first estrus in gilts. Whereas several GWASs have been done for age at puberty in pigs (Tart et al. 2013; Nonneman et al. 2014; Lucot et al. 2015), few have tested for associations with SNPs in candidate genes identified through GWASs. The current study, in which annotated candidate genes located within QTL identified through GWASs were screened for putative functional variants that could alter protein function, addresses this issue. The presence of these potential functional SNPs was confirmed in the discovery population with targeted genotyping, and the resulting analysis revealed 
Table 1 SNP with significant associations with age at puberty after correction for multiple testing.

\begin{tabular}{|c|c|c|c|c|c|c|c|c|c|}
\hline SNP name ${ }^{1}$ & rs number & SSC & Position $^{2}$ & Freq + Allele $^{3}$ & Effect $^{4}$ & $P$-value & Gene & *Variant & + Allele $^{5}$ \\
\hline $2: 55523775$ & rs341366698 & 2 & 54835723 & 0.685 & 3.57 & $3.13 E-06$ & $O R 2 M 4$ & MTC & A \\
\hline $7: 63472874$ & rs331221549 & 7 & 58784274 & 0.673 & -1.91 & $1.75 \mathrm{E}-04$ & CYP1A2 & RTG & G \\
\hline 8:30881914 & rs331381710 & 8 & 29483467 & 0.687 & -2.18 & $1.12 \mathrm{E}-04$ & $T B C 1 D 1$ & AAR & G \\
\hline 9:95536780 & rs345994568 & 9 & 86549936 & 0.631 & 2.18 & $1.03 E-07$ & $A H R$ & MCT & A \\
\hline 9:95537388 & rs696044913 & 9 & 86550544 & 0.501 & 1.61 & $3.35 \mathrm{E}-04$ & $A H R$ & CTA/- & Ins \\
\hline 9:95537517 & rs700345965 & 9 & 86550673 & 0.601 & -2.35 & $3.89 E-04$ & $A H R$ & $12 \mathrm{bp}$ indel & Ins \\
\hline 9:95537674 & rs339939442 & 9 & 86550830 & 0.499 & -2.46 & $8.23 E-08$ & $A H R$ & KGT & G \\
\hline 9:95540357 & rs339238482 & 9 & 86553513 & 0.499 & 2.49 & $5.63 E-08$ & $A H R$ & MCT & A \\
\hline 10:18351288 & rs334497829 & 10 & 16359010 & 0.842 & -2.26 & $1.60 \mathrm{E}-04$ & SDCCAG8 & GAY & C \\
\hline $12: 40342567$ & rs321145963 & 12 & 38741298 & 0.127 & 3.83 & 2.97E-09 & $A C A C A$ & -5 sccag & $\mathrm{C}$ \\
\hline
\end{tabular}

${ }^{1}$ SNP names derived from Sscrofa10.2 assembly.

${ }^{2}$ Position of variant in Sscrofa11.1 assembly.

${ }^{3}$ Frequency of positive allele associated with shorter age at puberty

${ }^{4}$ Effect in days.

${ }^{5}$ Positive allele associated with shorter age at puberty.

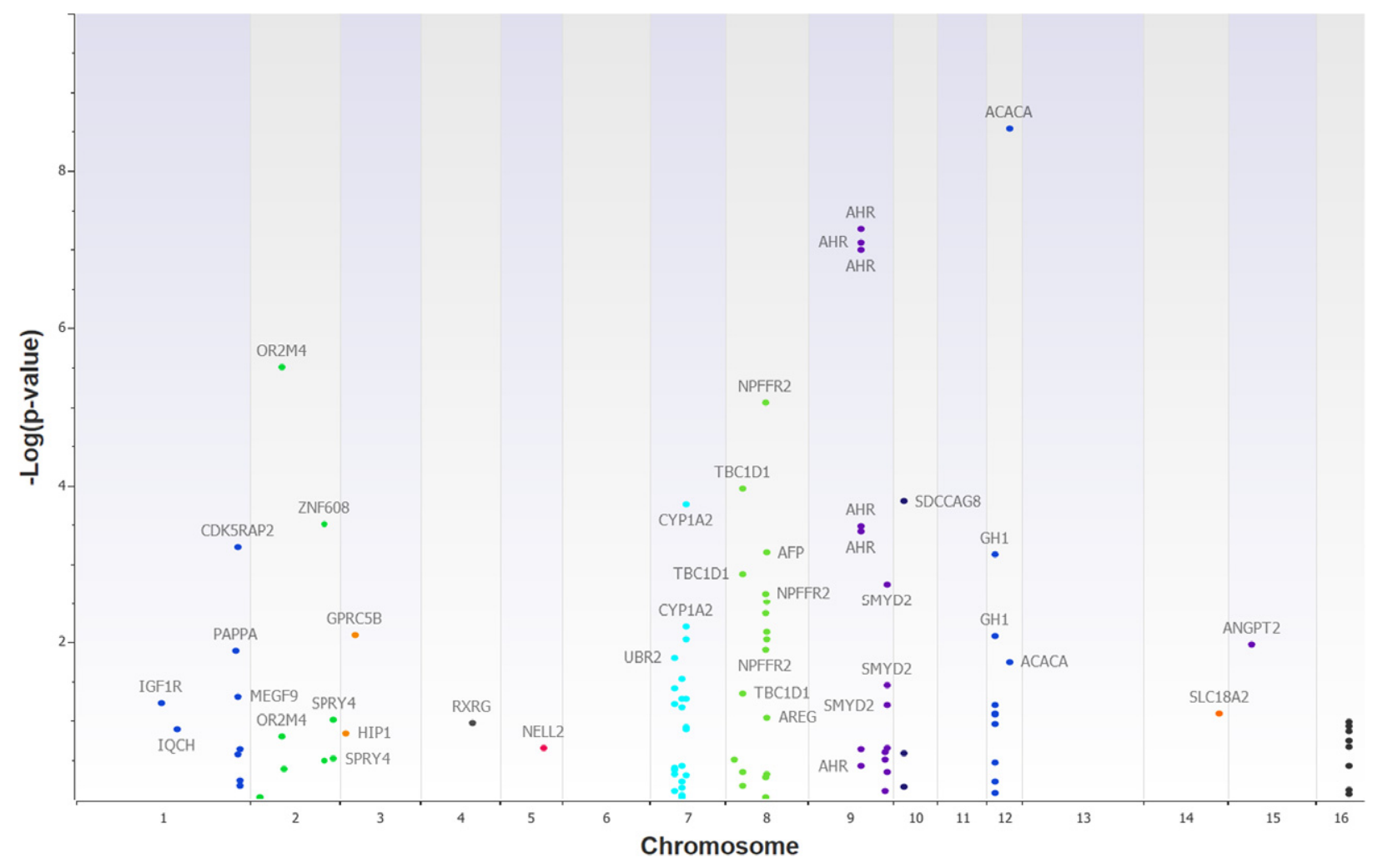

Figure 2 Genotypic associations from the mixed model REML analysis with fixed effects of year, season and sire breed.

several of these SNPs to be associated with age at puberty in gilts. The associated SNP is located within genes known to affect the growth and function of the hypothalamicpituitary-gonadal axis.

It is well understood that puberty in the pig is metabolically gated (Lents et al. 2020). Many of the candidate genes identified in the current study such as, SDCCAG8 (Scherag et al. 2012; Volckmar et al.2016) and TBC1D1 (Fontanesi \& Bertolini 2013; Volckmar et al. 2016), have been shown to be associated with body mass index, fatness and body composition traits in humans and pigs. The most significant SNP found resides in a splice site in ACACA, which catalyzes the rate-limiting step in fatty acid biosynthesis through the carboxylation of acetyl CoA to malonyl-CoA. Gene expression levels and genetic markers of ACACA have been associated with fatness traits in pigs (Gallardo et al. 2009; Eusebi et al. 2017; Fu et al. 2020; Piórkowska et al. 2020). Hypothalamic malonyl-CoA is implicated in food intake and 


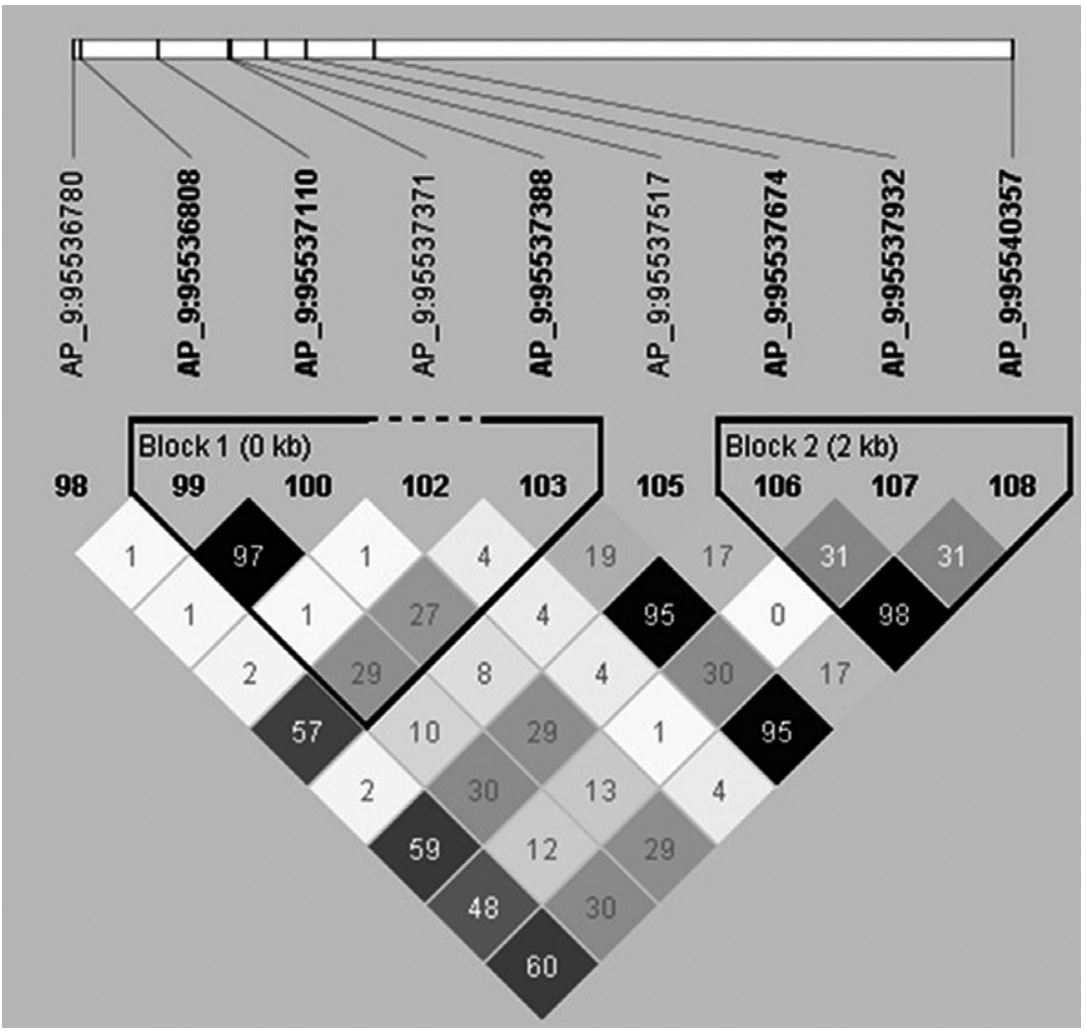

Figure $3 \mathrm{LD}\left(r^{2}\right)$ plot of $A H R$ markers analyzed.

Table 2 AHR allelic associations of AHR, CYP1A1 and CYP1A2 gene expression in liver by ddPCR normalized to PPIA expression.

\begin{tabular}{lllll}
\hline \multirow{5}{*}{ Marker } & \multicolumn{4}{l}{ AHR polymorphism } \\
\cline { 2 - 5 } & $9: 95537388$ & $9: 95537517$ & $9: 95537674$ & $9: 95540357$ \\
\hline Variant $^{2}$ & L/- & QQDL/- & G/C & T/P \\
AHR $^{3}$ & 0.0142 & 0.5013 & 0.1190 & 0.1190 \\
CYP1A1 & 0.0100 & 0.1560 & 0.3575 & 0.3575 \\
CYP1A2 & 0.4430 & 0.0363 & 0.9355 & 0.9355 \\
\hline
\end{tabular}

${ }^{1}$ Data represent allelic associations of $A H R$ genotypes analyzed using a mixed model linear regression using year as a fixed effect to account for sire breed and time of collection.

${ }^{2}$ Amino acid variants are shown below marker name.

${ }^{3}$ Values in table represent unadjusted $P$-values for allelic associations of $A H R$ genotypes.

energy homeostasis (Lane et al. 2005; Wolfgang \& Lane 2006; Gao et al. 2007), which are tightly linked to reproductive success (Schneider 2004; Zhuo et al. 2014; McIlwraith \& Belsham 2020) and human age at menarche (Speliotes et al. 2010; Day et al. 2015; Howard \& Dunkel 2018). Increasing free fatty acids concentrations within normal physiological levels increased the secretion of luteinizing hormone in gilts owing to an increase in the responsiveness of the anterior pituitary to gonadotropinreleasing hormone (Barb et al. 1991). It is likely that functional variants of these candidate genes lead to metabolic changes that are sensed by the hypothalamus and alter the pulsatile secretion of gonadotropin hormones, which drives the final maturation of ovarian follicles to a steroidogenic state that triggers puberty.

Several SNPs in exons 10 and 11 of AHR were associated with age at puberty. Exon 10 of the human $A H R$ is the most polymorphic region in the gene (Harper et al. 2002). These SNPs in the porcine AHR gene lie in subdomains of the transactivation domain of the receptor (Kumar et al. 2001). Whereas the acidic, Q-rich and P/S/T-rich subdomains are conserved across species, the amino acid sequences are less conserved. The four-codon QQDL insertion is unique to the pig and the one-codon leucine insertion is in a less conserved region. AHR is a ligand-activated transcription factor commonly known for its detoxifying function of dioxin (2,3,7,8-tetrachlorodibenzo-p-dioxin). In addition to responding to xenobiotics, such as dioxin, polychlorinated biphenyls, phthalates and other endocrine disruptors commonly found in the environment (Larigot et al. 2018), AHR also interacts with estrogen receptors through HSP90 (Chang et al. 2014). Activation of AHR action is through the AHR repressor and the induction of the cytochrome P450 enzymes CYP1A1, CYP1A2 and CYP1B1 (Larigot et al. 2018), which have high activity for the metabolism of estrogen (Lee et al. 2003; Tsuchiya et al. 2004). The CYP1A1 and CYP1A2 genes are bidirectionally positioned in the genome and are served by a common promoter region (Ueda et al. 2006) that is activated by AHR binding (Monostory et al. 2009). Polymorphisms in AHR have been 
shown to influence the expression of genes downstream in the pathways of AHR (CYP1A genes) and its own expression (Helmig et al. 2011). Consistent with this, gene expression of AHR, CYP1A1 and CYP1A2 in the current study was affected by SNPs in AHR. In the absence of a ligand, AHR constitutively represses fatty acid synthesis by ACACA, FASN and SCD1 enzymes (Tanos et al. 2012) and when activated further represses the expression of these genes. The role of AHR has been highly implicated in the female reproductive system for ovarian function, cyclicity and fertility (reviewed in Hernández-Ochoa et al. 2009) and has been identified in selection signature in independent studies in pigs (Bosse et al. 2014; Wang et al. 2017).

The results of this study associated polymorphisms in candidate genes identified from previous GWAS results with differences in age at puberty in pigs. The SNPs within these candidate genes that were examined in this study were chosen because they were expected to result in functional changes of the protein product. Polymorphisms in AHR linked to altered expression of downstream target genes demonstrates the functional consequences of these polymorphisms and supports this assumption. Moreover, these results implicate AHR-mediated pathways and putative functional polymorphisms in regulating the pubertal development of gilts. The AHR gene is critical in coordinating a physiological response to environmental contaminants such as plasticizers and endocrine disruptors that are known to cause perturbations in reproductive function. It may be speculated that differences in age at puberty in gilts could partly result from subtle differences in their physiological response to these environmental compounds.

\section{Acknowledgements}

The authors acknowledge the US Meat Animal Research Center (USMARC, Clay Center, NE, USA) swine crew for expert animal husbandry and data collection, Amber Moody for manuscript preparation and Brett Brockman, Kris Simmerman and Shanda Watts for genotyping and tissue collection.

\section{Data availability statement}

The genotypic and phenotypic data has been deposited in the OSF Data Repository (https://osf.io/) and is registered under project name Age at Puberty Candidate Genes, entry uz83x.

\section{References}

Barb C.R., Kraeling R.R., Barrett J.B., Rampacek G.B., Campbell R.M. \& Mowles T.F. (1991) Serum glucose and free fatty acids modulate growth hormone and luteinizing hormone secretion in the pig. Proceedings of the Society for Experimental Biology and Medicine 198, 636-42.
Bergfelder-Drüing S., Grosse-Brinkhaus C., Lind B., Lind B., Erbe M., Schellander K., Simianer H. \& Tholen E. (2015) A genome-wide association study in large white and landrace pig populations for number piglets born alive. PLoS One 10, e0117468.

Bosse M., Megens H.J., Frantz L.A. et al. (2014) Genomic analysis reveals selection for Asian genes in European pigs following human-mediated introgression. Nature Communications 15 , 4392.

Calderón Díaz J.A., Vallet J.L., Lents C.A. et al. (2015) Age at puberty, ovulation rate, and uterine length of developing gilts fed two lysine and three metabolizable energy concentrations from 100 to 260 d of age. Journal of Animal Science 93, 3521-7.

Chang Z., Lu M., Kim S.S. \& Park J.S. (2014) Potential role of HSP90 in mediating the interactions between estrogen receptor (ER) and aryl hydrocarbon receptor (AhR) signaling pathways. Toxicology Letters 226, 6-13.

Day F.R., Perry J.R. \& Ong K.K. (2015) Genetic regulation of puberty timing in humans. Neuroendocrinology 102, 247-55.

Engblom L., Lundeheim N., Strandberg E., Schneider Mdel P., Dalin A.M. \& Andersson K. (2008) Factors affecting length of productive life in Swedish commercial sows. Journal of Animal Science 86, 432-41.

Eusebi P.G., González-Prendes R., Quintanilla R., Tibau J., Cardosa T.F., Clop A. \& Amills M. (2017) A genome-wide association analysis for carcass traits in a commercial Duroc pig population. Animal Genetics 48, 466-9.

FASS (Federation of Animal Science Societies) (2010). Guide for the Care and Use of Agricultural Animals in Research and Teaching, 3rdedn. Federation of Animal Science Societies, Champaign, IL.

Fontanesi L. \& Bertolini F. (2013) The TBC1D1 gene: structure, function, and association with obesity and related traits. Vitamins and Hormones 91, 77-95.

Foxcroft G.R., Dixon W.T., Dyck M.K., Novak S., Harding J.C. \& Almeida F.C. (2009) Prenatal programming of postnatal development in the pig. Society of Reproduction and Fertility Supplement 66, 213-31.

Fu Y., Wang L., Tang Z., Yin D., Xu J., Fan Y., Li X., Zhao S. \& Liu X. (2020) An integration analysis based on genomic, transcriptomic and QTX information reveals credible candidate genes for fatrelated traits in pigs. Animal Genetics 51, 683-93.

Gallardo D., Quintanilla R., Varona L., Diaz I., Ramirez O., Pena R.N. \& Amills M. (2009) Polymorphism of the pig acetylcoenzyme A carboxylase alpha gene is associated with fatty acid composition in a Duroc commercial line. Animal Genetics 40, $410-7$.

Gao S., Kinzig K.P., Aja S. et al. (2007) Leptin activates hypothalamic acetyl-CoA carboxylase to inhibit food intake. Proceedings of the National Academy of Sciences of the United States of America 104, 17358-63.

Harper P.A., Wong J.M., Lam M.S. \& Okey A.B. (2002) Polymorphisms in the human AH receptor. Chemico-Biological Interactions 141, 161-87.

Helmig S., Seelinger J.U., Döhrel J. \& Schneider J. (2011) RNA expressions of AHR, ARNT and CYP1B1 are influenced by AHR Arg554Lys polymorphism. Molecular Genetics and Metabolism 104, 180-4.

Hernández-Ochoa I., Karman B.N. \& Flaws J.A. (2009) The role of the aryl hydrocarbon receptor in the female reproductive system. Biochemical Pharmacology 77, 547-59. 
Howard S.R. \& Dunkel L. (2018) The genetic basis of delayed puberty. Neuroendocrinology 106, 283-91.

Keel B.N., Nonneman D.J. \& Rohrer G.A. (2017) A survey of single nucleotide polymorphisms identified from whole-genome sequencing and their functional effect in the porcine genome. Animal Genetics 48, 404-11.

Knox R.V. (2019) PHYSIOLOGY AND ENDOCRINOLOGY SYMPOSIUM: Factors influencing follicle development in gilts and sows and management strategies used to regulate growth for control of estrus and ovulation. Journal of Animal Science 97, 1433-45.

Kumar M.B., Ramadoss P., Reen R.K., Vanden Heuvel J.P. \& Perdew G.H. (2001) The Q-rich subdomain of the human Ah receptor transactivation domain is required for dioxin-mediated transcriptional activity. Journal of Biological Chemistry 276, $42302-10$

Lane M.D., Hu Z., Cha S.H., Dai Y., Wolfgang M. \& Sidhaye A. (2005) Role of malonyl-CoA in the hypothalamic control of food intake and energy expenditure. Biochemical Society Transactions 33, 1063-7.

Larigot L., Juricek L., Dairou J. \& Coumoul X. (2018) AhR signaling pathways and regulatory functions. Biochimie Open 7, 1-9.

Lee A.J., Cai M.X., Thomas P.E., Conney A.H. \& Zhu B.T. (2003) Characterization of the oxidative metabolites of 17 beta-estradiol and estrone formed by 15 selectively expressed human cytochrome p450 isoforms. Endocrinology 144, 3382-98.

Lents C.A., Lindo A.N., Hileman S.M. \& Nonneman D.J. (2020) Physiological and genomic insight into neuroendocrine regulation of puberty in gilts. Domestic Animal Endocrinology 73, 106446.

Li Q., Yuan X., Chen Z., Zhang A., Zhang Z., Zhang H. \& Li J. (2018) Heritability estimates and effect on lifetime reproductive performance of age at puberty in sows. Animal Reproduction Science 195, 207-15.

Lucot K.L., Spangler M.L., Trenhaile M.D., Kachman S.D. \& Ciobanu D.C. (2015) Evaluation of reduced subsets of single nucleotide polymorphisms for the prediction of age at puberty in sows. Animal Genetics 46, 403-9.

Matsuyama S. \& Kimura K. (2014) Regulation of gonadotropin secretion by monitoring energy availability. Reproductive Medicine and Biology 14, 39-47.

McIlwraith E.K. \& Belsham D.D. (2020) Hypothalamic reproductive neurons communicate through signal transduction to control reproduction. Molecular and Cellular Endocrinology 518, 110971.

Monostory K., Pascussi J.-M., Kóbori L. \& Dvorak Z. (2009) Hormonal regulation of CYP1A expression. Drug Metabolism Reviews 41, 547-72.

Nonneman D., Lents C., Rohrer G., Rempel L. \& Vallet J. (2014) Genome-wide association with delayed puberty in swine. Animal Genetics 45, 130-2.

Nonneman D.J., Schneider J.F., Lents C.A., Wiedmann R.T., Vallet J.L. \& Rohrer G.A. (2016) Genome-wide association and identification of candidate genes for age at puberty in swine. BMC Genetics 17, 50 .

Onteru S.K., Fan B., Du Z.Q., Garrick D.J., Stalder K.J. \& Rothschild M.F. (2012) A whole-genome association study for pig reproductive traits. Animal Genetics 43, 18-26.

Onteru S.K., Fan B., Nikkilä M.T., Garrick D.J., Stalder K.J. \& Rothschild M.F. (2011) Whole-genome association analyses for lifetime reproductive traits in the pig. Journal of Animal Science 89, 988-95.

Patterson J.L., Beltranena E. \& Foxcroft G.R. (2010) The effect of gilt age at first estrus and breeding on third estrus on sow body weight changes and long-term reproductive performance. Journal of Animal Science 88, 2500-13.

Piórkowska K., Małopolska M., Ropka-Molik K., Szyndler-Nędza M., Wiechniak A., Żukowski K., Lambert B. \& Tyra M. (2020) Evaluation of SCD, ACACA and FASN mutations: effects on pork quality and other production traits in pigs selected based on RNA-Seq results. Animals (Basel) 10, 123.

Rothschild M.F. \& Bidanel J.P. (1998) Biology and genetics of reproduction. In: Genetics of the Pig (Ed. by Rothschild M.F., Ruvinsky A.), pp. 313-43. CABI, University Press, Cambridge, UK.

Saito H., Sasaki Y., Koketsu Y. (2011) Associations between age of gilts at first mating and lifetime performance or culling risk in commercial herds. Journal of Veterinary Medical Science 73, 5559.

Scherag A., Kleber M., Boes T. et al. (2012) SDCCAG8 obesity alleles and reduced weight loss after a lifestyle intervention in overweight children and adolescents. Obesity 20, 466-70.

Schneider J.E. (2004) Energy balance and reproduction. Physiology E Behavior 81, 289-317.

Schneider J.F., Nonneman D.J., Wiedmann R.T., Vallet J.L. \& Rohrer G.A. (2014) Genomewide association and identification of candidate genes for ovulation rate in swine. Journal of Animal Science 92, 3792-803.

Schneider J.F., Rempel L.A., Snelling W.M., Wiedmann R.T., Nonneman D.J. \& Rohrer G.A. (2012) Genome-wide association study of swine farrowing traits. Part II: Bayesian analysis of marker data. Journal of Animal Science 90, 3360-7.

Speliotes E.K., Willer C.J., Berndt S.I. et al. (2010) Association analyses of 249,796 individuals reveal 18 new loci associated with body mass index. Nature Genetics 42, 937-48.

Tanos R., Murray I.A., Smith P.B., Patterson A. \& Perdew G.H. (2012) Role of the Ah receptor in homeostatic control of fatty acid synthesis in the liver. Toxicological Sciences 129, 372-9.

Tart J.K., Johnson R.K., Bundy J.W. et al. (2013) Genome-wide prediction of age at puberty and reproductive longevity in sows. Animal Genetics 44, 387-97.

Trenhaile M.D., Petersen J.L., Kachman S.D., Johnson R.K. \& Ciobanu D.C. (2016) Long-term selection for litter size in swine results in shifts in allelic frequency in regions involved in reproductive processes. Animal Genetics 47, 534-42.

Tsuchiya Y., Nakajima M. \& Yokoi T. (2005) Cytochrome P450mediated metabolism of estrogens and its regulation in human. Cancer Letters 227, 115-24.

Ueda R., Iketaki H., Nagata K. et al. (2006) A common regulatory region functions bidirectionally in transcriptional activation of the human CYP1A1 and CYP1A2 genes. Molecular Pharmacology 69, 1924-30.

Uimari P., Sironen A. \& Sevón-Aimonen M.L. (2011) Wholegenome SNP association analysis of reproduction traits in the Finnish Landrace pig breed. Genetics Selection Evolution 43, 42.

Volckmar A.L., Han C.T., Pütter C. et al. (2016) Analysis of genes involved in body weight regulation by targeted re-sequencing. PLoS One 11, e0147904. 
Wang J., Zou H., Chen L. et al. (2017) Convergent and divergent genetic changes in the genome of Chinese and European pigs. Scientific Reports 17, 8662.

Wolfgang M.J. \& Lane M.D. (2006) The role of hypothalamic malonyl-CoA in energy homeostasis. Journal of Biological Chemistry 281, 37265-9.

Zhuo Y., Zhou D., Che L., Fang Z., Lin Y. \& Wu D. (2014) Feeding prepubescent gilts a high-fat diet induces molecular changes in the hypothalamus-pituitary-gonadal axis and predicts early timing of puberty. Nutrition 30, 890-6.

\section{Supporting information}

Additional supporting information may be found online in the Supporting Information section at the end of the article.

Table S1. Summary statistics for age at puberty for animals used in this study.

Table S2. Summary of SNP variants and associations with age at puberty in gilts.

Table S3. Primers used for quantitative gene expression by ddPCR. 